Int. J. Electrochem. Sci., 12 (2017) $3883-3906$

\title{
Integration of Ruthenium oxide-Carbon Nanotube Composites with Three-Dimensional Interdigitated Microelectrodes for the Creation of On-Chip Supercapacitors
}

\author{
Yajiang Yin, Xiaofeng Wang ${ }^{*}$, Zheng You \\ Department of Precision Instrument, Tsinghua University, No.1 Tsinghua Yuan, Haidian District, \\ Beijing, P. R. China \\ *E-mail: xfw@tsinghua.edu.cn
}

doi: $10.20964 / 2017.05 .39$

Received: 22 February 2017 / Accepted: 19 March 2017 / Published: 12 April 2017

A three-dimensional (3D) on-chip supercapacitor is fabricated by performing deep-ultraviolet lithography on a SU-8 photoresist. By using a cathodic deposition technique, ripple-like ruthenium oxide-carbon nanotube nanocomposites are synthesized. The carbon nanotube (CNT) network in the nanocomposite makes the electrolyte penetration easier and facilitates proton exchange and diffusion. A specific capacitance of $208.5 \mathrm{mF} \cdot \mathrm{cm}^{-2}$ is achieved at $10 \mathrm{mV} \cdot \mathrm{s}^{-1}$ in a neutral $\mathrm{Na}_{2} \mathrm{SO}_{4}$ solution. The interdigitated cell forms a supercapacitor when it is placed on a chip, and exhibits many desirable properties; the specific capacitance of as high as $28.70 \mathrm{mF} \cdot \mathrm{cm}^{-2}$ is achieved at $120 \mathrm{~mA} \cdot \mathrm{cm}^{-2}$. The highest energy density $\left(25.99 \mathrm{~mJ} \cdot \mathrm{cm}^{-2}\right)$ and the highest power density $\left(46.92 \mathrm{~mW} \cdot \mathrm{cm}^{-2}\right)$ are also achieved with the interdigitated micro-supercapacitor. Therefore, 3D microstructures made with electrochemically deposited carbon nanotube composites are promising candidates for application as on-chip supercapacitors.

Keywords: On-chip supercapacitor; Ruthenium oxide; Carbon nanotubes; Interdigitated microstructures; Micro-electro-mechanical systems.

\section{FULL TEXT}

(C) 2017 The Authors. Published by ESG (www.electrochemsci.org). This article is an open access article distributed under the terms and conditions of the Creative Commons Attribution license (http://creativecommons.org/licenses/by/4.0/). 